\title{
Static behavior of CFRPs at low temperatures
}

\author{
S. Sánchez-Sáez, T. Gómez-del Río, E. Barbero, R. Zaera, C. Navarro* \\ Department of Mechanical Engineering, Carlos III University of Madrid, Avda. de la Universidad 30, 28911 Leganés, Madrid, Spain
}

\begin{abstract}
This paper summarizes the results of the tests to determine the effect of the low temperature on the mechanical behavior of carbon fiber reinforced epoxy laminates. Tensile and bending static tests were carried out on two laminate lay ups (quasi isotropic and cross ply laminates), determining properties such as the mechanical strength, stiffness and strain to failure. The results show the changes in the mechanical behavior of this material at different test temperatures $\left(20, \quad 60\right.$ and $\left.\quad 150{ }^{\circ} \mathrm{C}\right)$.
\end{abstract}

Keywords: A. Polymer matrix composites; B. Strength; D. Mechanical testing; Low temperature

\section{Introduction}

Future generations of launcher vehicles will have to be completely reusable in order to achieve a reliable access to space at much lower cost than is possible with today's expendable launch vehicles (Ariane 5 type) or semi expendable (Space Shuttle type), so it is necessary to reduce the structural mass of the vehicles because dry weight is a major cost driver [1]. In this regard, fuel tanks and propellant masses in a launcher represent an important mass fraction (about $90 \%$ of the total mass) [2].

Carbon fiber reinforced epoxy composites (CFRPs) are one of the enabling materials to reduce the structural mass. CFRPs are often used in the production of structural components for the aeronautics and aerospace industries, mainly because of their excellent specific mechanical properties and their high resistance to fatigue, and of the possibility of selecting the optimum laminate lay up for each application. Besides these properties, low thermal conductivity and high dimensional stability have made the CFRPs a good alternative for applications where very low temperatures are reached, such as in cryogenic tanks and their support elements.

During their operational life in these applications, the CFRPs are subjected to low temperatures that could modify the mechanical properties of the material. These conditions affect the mechanical properties of the material by two

\footnotetext{
* Corresponding author. Tel.: +349162494 91; fax: +349162494 30.

E-mail address: navarro@ing.uc3m.es (C. Navarro).
}

reasons [3,4]: (a) the variation of the properties of the constituents of the material and (b) the appearance of residual stresses inside the material due to the mismatch between the thermal expansion coefficients of fibers and of the matrix. It is necessary, therefore, to carry out a mechanical characterization over the complete range of temperatures that can be reached during the operational life of components made of these materials [5].

The experimental characterization of materials at low temperatures calls for special test equipment and instru mentation, which increases the difficulty of obtaining valid results. Although the behavior of these materials at low temperatures have been analyzed by several authors [3 18$]$, few experimental results are available and no standardized test method has been fixed [5].

Rogers et al. [6] studied the thermal expansion coefficient variation with temperature in high modulus and high strength carbon fiber unidirectional laminates. They observed that the thermal expansion coefficient in the fiber direction tends to increase as temperature decreases whereas the opposite occurs in the laminate transverse direction. Kriz [7] analyzed the static behavior in tension of quasi isotropic graphite fiber laminates from room temperature to

$196{ }^{\circ} \mathrm{C}$. The laminate strength diminished by about $8 \%$ at low temperatures due to the residual stress as well to humidity in the test. Wilson and Bashford [8] studied different types of CFRPs (different carbon fibers) for temperatures to $260{ }^{\circ} \mathrm{C}$ for unidirectional laminates, analyzing the properties in both longitudinal and transverse directions, and for cross ply laminates $\left( \pm 45^{\circ}\right)$. The measured Young modulus in the longitudinal direction 
and in tensile conditions remained practically constant. In the other two situations, this modulus tends to increase at low temperature and thus the stiffness of the laminate is increased. The tensile strength (TS) decreases however with decreasing temperature. This effect becomes much more evident when the fibers in the laminate are not parallel to the applied load direction. In compression conditions, the material strength tends to improve with the lowering of the temperature when the fibers are oriented at 0 or $\pm 45^{\circ}$ from the load direction. Dutta et al. [9] analyzed the behavior of quasi isotropic CFRP laminates subjected to impact loads at low velocity for temperatures ranging from 20 to $69^{\circ} \mathrm{C}$. They observed that the absorbed energy of the laminate showed little dependence on temperature. Adams and Gaitonde [10] carried out dynamic bending tests of carbon fiber laminates in thermoplastic matrices (PEEK and HTA) in vacuum conditions at temperatures as low as

$196{ }^{\circ} \mathrm{C}$. They observed that in both matrices there was a reduction of the bending modulus as the temperature was lowered. Dutta [4] considered the behavior of unidirectional laminates of glass fiber/polyester in compression conditions at $48{ }^{\circ} \mathrm{C}$. Their Young modulus, as well as their strength, increases at low temperature. Reed and Golda [11] studied different properties of unidirectional laminates with different types of fibers (boron, alumina, aramide, glass and carbon) in an epoxy matrix. They gave thermal, electric and mechanical properties of CFRPs, in both tensile and compression conditions, for temperatures to $269^{\circ} \mathrm{C}$. In tensile conditions, the Young modulus increases moderately in all the fibers as the temperature decreases, the larger increments being for boron, aramide and high modulus carbon composites. The TS rose significatively at low temperature, the lowest increment being for aramide and HM carbon fiber composites. In compression conditions the mechanical strength of the alumina and boron fiber composites also increased as the temperature decreased, whereas it remained practically constant in the laminates of aramide and carbon fibers. Karasec et al. [12] observed that the impact behavior of carbon fiber in different matrices and at temperatures ranging from 23 up to $66^{\circ} \mathrm{C}$ seems to be dependent also on humidity. Shindo and Ueda [13] carried out numerical simulation to study the residual stress influence on the mechanical properties of glass fiber/ epoxy laminate with cracks. Nettles and Biss [14] carried out mechanical tests at $196^{\circ} \mathrm{C}$ on $45^{\circ}$ angle ply of carbon fiber/epoxy laminates. They analyzed the effect of tempera ture on those properties governed by the matrix behavior such as shear strength, and they tested the same materials in tensile conditions but with a stacking sequence of $[+45 /$ 0/ 45/90 $]_{\mathrm{s}}$. They found that the matrix stiffens and that shear strength and shear modulus of the laminate increases as the temperature is lowered (from $94 \mathrm{MPa}$ and $5.6 \mathrm{GPa}$, at room temperature, to $102 \mathrm{MPa}$ and $8.1 \mathrm{GPa}$ at $196^{\circ} \mathrm{C}$ ). In the quasi isotropic laminate, they observed a linear elastic behavior until rupture. As the temperature decreased, the laminate TS fell slightly (from $762 \mathrm{MPa}$ at room tempera ture to $695 \mathrm{MPa}$ at $196^{\circ} \mathrm{C}$ ) and the Young modulus increased (from $62 \mathrm{MPa}$ at room temperature to $64 \mathrm{MPa}$ at

$196^{\circ} \mathrm{C}$ ). Hübner and Hartwing [15] studied the static and fatigue behavior of cross ply carbon fiber in different matrices for temperatures to $196{ }^{\circ} \mathrm{C}$. They observed that the fatigue behavior was strongly conditioned by the kind of matrix used. Carrión et al. [16] made tests in tensile, compression and shear conditions on carbon fiber/cyanate resin cross ply laminates reaching temperatures to

$253{ }^{\circ} \mathrm{C}$. They observed an increase of Young modulus and a decrease of both TS and rupture strain at low temperatures. In the other tests they observed that properties decreased a little under compression and shear strength remained constant as temperature decreased. Baschek and Hartwing [17] computed the thermal stresses in an industrial piece manufactured with graphite fiber cross ply laminates subjected to thermal loading at temperatures ranging from

50 up to $179^{\circ} \mathrm{C}$, taking into account the temperature dependence on the thermal expansion coefficients of the materials. Schutz [3] summarized the quasi static properties of different polymer matrix composite materials at tem peratures ranging from 20 to $269^{\circ} \mathrm{C}$. In CFRP uni directional laminates, the Young modulus and the ultimate tensile stress increase as the temperature decreases. In compression conditions, the strength tends to rise slightly with this decrease. Pintado et al. [5] analyzed the temperature effect on unidirectional laminates of carbon fiber in a cyanate thermoset resin. For the interlaminar shear strength they also analyzed two different epoxy resins. Their aim was to select a material suitable for future launcher vehicles. They defined the methodology used for tests in compression, tensile, bending, in plane shear, interlaminar shear and Mode II fracture, at temperatures of about $20 \mathrm{~K}$. They observed a slight drop of the compression and the TS in both the longitudinal and transverse laminate directions. The in plane strength was not apparently affected by the low temperature although, the apparent interlaminar shear strength increased by $50 \%$. All the materials showed an increment of their stiffness at low temperature, especially in the transverse fiber direction. Kim et al. [18] studied fracture properties (fracture toughness in mode I) of CFRPs taking into account the fiber orientation and the lower of temperature. Aoki et al. [19] analyzed basic properties (elastic properties, thermal expansion coefficient and mechanical strength) of different carbon fiber composites used in cryogenic tanks to $269^{\circ} \mathrm{C}$. They considered different matrices: epoxy, bismaleimide and PEEK. In unidirectional laminates they measured $E_{1}, E_{2}, G_{12}$ and $\nu_{21}$ and the thermal expansion coefficients $\alpha_{1}$ and $\alpha_{2}$, and found that the properties most affected by the fall in the temperature were those controlled by the matrix. They also conducted tensile tests on quasi isotropic laminates $\left([+45 / 0 / 45 / 90]_{2 \mathrm{~s}}\right)$ which showed a reduction, at room temperature of the mechanical strength, of about $80 \%$ at a temperature of $269^{\circ} \mathrm{C}$.

Most of the mechanical tests at low temperature on 
CFRPs have been done for unidirectional and quasi isotropic laminates. Few data are available for cross ply laminates as a comparison of their properties with those of the quasi isotropic ones. Little is known about the behavior of such materials in bending behavior at low temperature. The main goal of this paper is to contribute to a better understanding of the behavior of these materials at low temperature, studying two typical lay up sequences (cross play and quasi isotropic laminates) of CFRP as well as their behavior in bending conditions at low temperature. All our tests were performed at temperatures of $20{ }^{\circ} \mathrm{C}$ (room temperature), $\quad 60^{\circ} \mathrm{C}$ (representative of a plane in flight) and $150{ }^{\circ} \mathrm{C}$ (representative of a satellite in orbit), to determine the effect of such temperatures on the mechanical behavior of the material.

\section{Materials and experimental tests}

The basic material selected for this research was AS4/3501 6 prepreg unidirectional tape, produced by HEXCEL and is composed of AS4 carbon fiber embedded in 35016 epoxy resin with a volumetric content of fibers of $60 \%$. Two different lay up sequences were used: cross ply $[0 / 90]_{3 \mathrm{~S}}$ and quasi isotropic $[ \pm 45 / 0 / 90]_{\mathrm{s}}$ laminates. $400 \times 400 \mathrm{~mm}^{2}$ plates were manufactured by SACESA in Seville (Spain). The thicknesses of the resulting laminates were: $2.4 \mathrm{~mm}$ for the cross play laminate and $1.6 \mathrm{~mm}$ for the quasi isotropic laminate. Specimens were cut from panels with a water jet. Two kinds of static tests were carried out: tensile tests and three point bending tests, all at different temperatures: 20 (room temperature), 60 and $150{ }^{\circ} \mathrm{C}$.

\subsection{Static tensile test}

The purpose of the static tensile tests was to determine the low temperature effect on the TS, the Young modulus and ultimate strain of the two laminates considered. Five tests were done for each temperature and laminate type, from which load displacement curves, the stress strain curves of the material were obtained.

Since no standard for low temperature static tensile tests has been developed, the recommendations of standard at ambient temperature were used [5]. The tests were carried out in a $100 \mathrm{kN}$ Instron universal testing machine. A climatic chamber was coupled to the testing machine. Low temperature was reached within the climatic chamber by means of liquid nitrogen. A $30 \mathrm{kN}$ grip and a longitudinal extensometer MTS of $12.5 \mathrm{~mm}$ gauge length and $+25 / 5 \mathrm{~mm}$ travel distance, were used, both specifically designed for use in low temperature tests.

To define the test specimen geometry, the ASTM 3039 standard for tensile tests at room temperature was used [20]. Due to the grips limitation ( $30 \mathrm{kN}$ of maximum load) it was necessary to reduce the specimen size, accordingly with the standard, to a $250 \times 12 \mathrm{~mm}^{2}$ straight sided specimen.

Although the ASTM 3039 standard suggests that tested specimens do not require tabs, previous tests showed that they should be used to avoid slipping phenomena in the gripping area. After a set of preliminary tests with different tab thicknesses, an aluminium tab of $1 \mathrm{~mm}$ thick was selected. For those configurations in which tabs were required, the above mentioned standard recommends a tab length of $56 \mathrm{~mm}$, but smaller tabs $(40 \mathrm{~mm})$ were used in the experiments to guarantee that the whole of the tab was pressed by the grips, thus avoiding the break in the tab ends. Otherwise, in the area of the specimen where the tab is not pressed by the grip, a phenomenon of stress concentration would cause peeling of the external fibers, a smaller effective transverse section, and breaking of the sample (Fig. 1). This phenomenon of stress concentration has been described by other authors [5].

Before carrying out the experiments, a previous cooling test was made but without applying any load. This allows to check the behavior of the whole testing system at $150{ }^{\circ} \mathrm{C}$. Because the load cell is in contact with other element inside the climatic chamber its cools, and an erratic signal was recorded which did not correspond to any real value of the applied load. To solve this problem, a special device was designed that thermally isolated the load cell (Fig. 2). This apparatus comprised a connecting hollow tube in which water circulates continually at ambient temperature.

\subsection{Static bending test}

One of the most common experiments to characterize materials in flexural conditions is the three point bending test. At low temperature, and once the climatic chamber was coupled to the testing machine, it was necessary to design a special bending device for low temperature testing. As in the tensile tests, there is no standard for static bending at low temperature, so the ASTM D790 98 standard for material testing at room temperature was used [21].

Straight side specimens of $20 \times 105 \mathrm{~mm}^{2}$, were used. The specimen support span was $80 \mathrm{~mm}$. A specimen support span depth ratio of 40 was chosen to check that specimen failure begins in the outer fibers (ratios between 32 and 40 are recommended in that standard). Load was applied at the specimen mid span at a strain rate of $0.01 \mathrm{~min}^{1}$. Seven tests were made for each configuration and temperature (standard recommends a minimum of five).

In the testing machine it is possible to record, at every instant of time, the force applied on the specimen and the displacement of the piston. To measure accurately the displacement at the specimen midspan at room temperature an LVDT extensometer is used. In the same manner, in low temperature tests, a longitudinal extensometer was adapted to operate in a similar way.

From the tests, the following material properties were determined: 


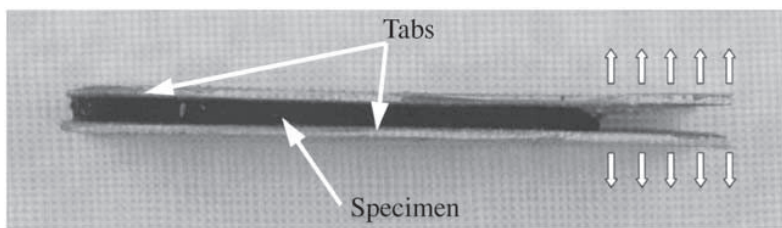

Fig. 1. Broken tensile specimen by stress concentration in the tabs end.

Flexural strength, obtained from the maximum load value as shown in Eq. (1) [21]

$\sigma_{\mathrm{f}}=\frac{3 P L}{2 b d^{2}}$

where $\sigma_{\mathrm{f}}$ is the flexural strength (maximum stress at mid span), $P$ the applied load that leads the specimen to fail, $L$ the support span, $b$ the specimen width and, finally, $d$ the specimen thick.

For support span depth ratios above 16:1, and when deflections are larger than $10 \%$ of the support span, Eq. (1) becomes inaccurate, so, the maximum stress at the mid span can be approximated by the following equation [22]

$\sigma_{\mathrm{f}}=\left(\frac{3 P L}{2 b d^{2}}\right)\left[1+6(D / L)^{2} \quad 4(d / L)(D / L)\right]$

$D$ being the deflection at mid span (mm)

Effective engineering modulus, which may be obtained from the slope of the initial straight line part of the load deflection curve by means of this equation:

$D=\frac{L^{3}}{48 I} \cdot \frac{F}{\delta}$ where $F / \delta$ represents the slope of the force displacement curve and $I$ the cross sectional inertia of the specimen.

\section{Results and discussion}

\subsection{Tensile tests results}

From the tensile test results, the stress strain curves were drawn. Fig. 3 shows this curve for the quasi isotropic laminate at the three different temperatures considered. The laminate exhibits a linear elastic behavior until breakage, and the slope of the stress strain curve increases slightly as the temperature decreases. The mean stiffness increment was very low (from $18 \mathrm{GPa}$, at room temperature, to $21 \mathrm{GPa}$, at $150{ }^{\circ} \mathrm{C}$ ) which seems to be very close to experimental error. However the TS and the ultimate tensile strain (UTS) drop significatively as the temperature becomes lower. The TS decreases from $520 \mathrm{MPa}$, at room temperature, to $340 \mathrm{MPa}$ at $150{ }^{\circ} \mathrm{C}$, whereas the UTS decreases from $2.92 \%$, at room temperature, to $1.58 \%$ at $150{ }^{\circ} \mathrm{C}$

Figs. 46 show the values of the TS, the Young modulus, and UTS, for quasi isotropic and cross ply laminates as a function of the test temperature, with the mean values and standard deviation of these material parameters. At room temperature, the Young modulus and the TS of the cross ply laminates are, respectively, 80 and $60 \%$ higher than those of quasi isotropic laminates. These percentages become 50 and $90 \%$, respectively at $150{ }^{\circ} \mathrm{C}$. It is also worth noting that the material stiffness effect induced by the temperature in the quasi isotropic laminate, is not observed in the
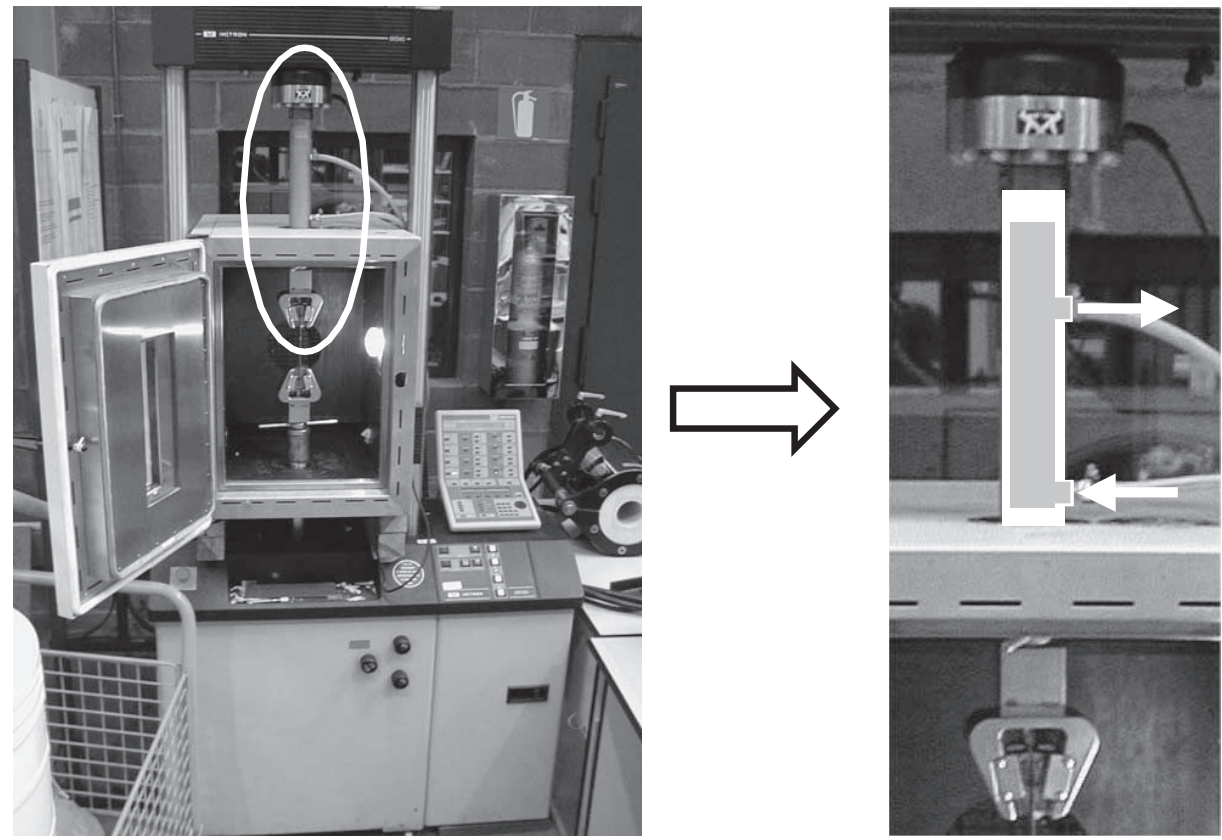

Fig. 2. Tensile test experimental set up (left) and detail of the device to isolate thermally the load cell (right). 


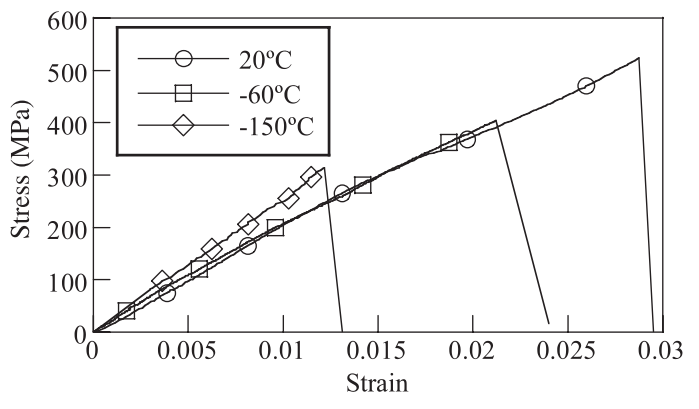

Fig. 3. Stress strain curve for quasi isotropic laminate at three different temperatures.

cross ply laminate. In this last case, the Young modulus is slightly lower (less than 7\%) as temperature decreases. However, the strength and ultimate strain reduction caused by temperature also appear in cross ply laminates. Whereas the magnitude of the stress reduction seems to be similar in both laminate types (although it is a little higher in the quasi isotropic laminate), the UTS change is much more pronounced in the quasi isotropic laminate than for the cross play one. The most important behavior difference between these two stacking sequences concerns the failure strains (Fig. 6). At room temperature, the quasi isotropic laminate UTS is $15 \%$ higher than that of the cross ply one, but at $150{ }^{\circ} \mathrm{C}$, the cross ply UTS becomes $30 \%$ higher than that of the quasi isotropic laminate. All these discussions show that, although both laminates have the same constituents, the staking strongly affects the mechan ical response.

Scanning electron microscopy of specimens broken in the tensile test show that the failure mechanism changes with temperature. In the quasi isotropic laminate at room temperature, the matrix fails first, leaving matrix debris on the fibers (Fig. 7(a)). As the temperature decreases, the fiber matrix interface becomes much weaker and the fibers debond from the matrix (Fig. 7(b) and (c)). It may be concluded that the lower temperature affects the micro mechanisms of damage.

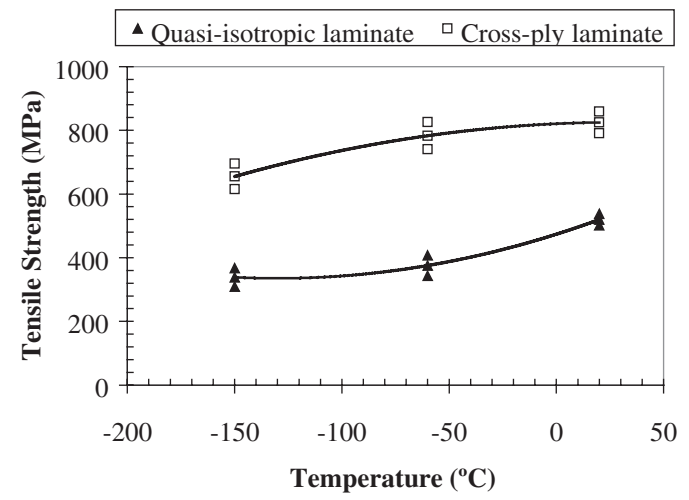

Fig. 4. Static tensile Young modulus versus temperature for cross ply and quasi isotropic laminates.

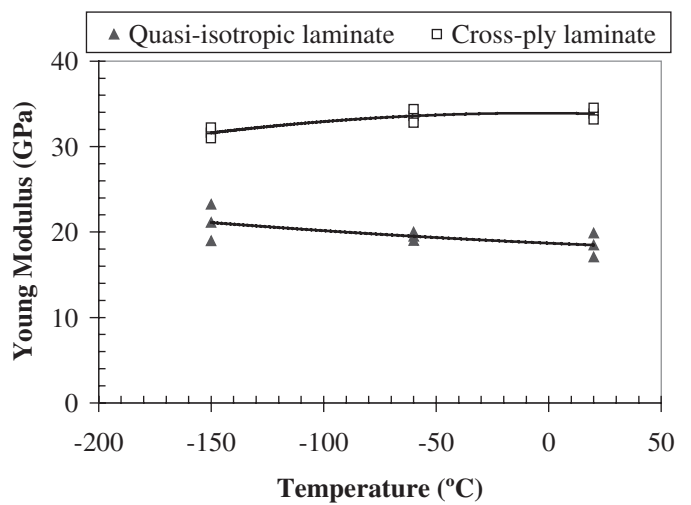

Fig. 5. Static TS versus temperature for cross ply and quasi isotropic laminates.

\subsection{Three point bending tests results}

From the three point bending test results, no full specimen failure was reached at any temperature, neither in the quasi isotropic (Fig. 8) nor in the cross ply (Fig. 9) laminates. These figures show that delamination damage increases as the test temperature decreases. Figs. 10 and 11 show a comparison between quasi isotropic and cross ply laminate behavior as a function of the test temperature. Mean values and standard deviation of the flexural strength and effective engineering modulus are shown in these two figures. Fig. 10 shows that the flexural strength of both laminates decreases as the temperature becomes lower. As in tensile conditions, bending strength is larger in the cross ply laminate than that of the quasi isotropic one (about 50 and $90 \%$ greater at room temperature and $150{ }^{\circ} \mathrm{C}$, respectively). In bending tests and for both laminates, the reduction of strength caused by temperature is similar. However, comparing percentages, the quasi isotropic laminate suffers a much great loss of strength. In the quasi isotropic laminate the strength drops from $865 \mathrm{MPa}$, at room temperature, to $517 \mathrm{MPa}$ at $150{ }^{\circ} \mathrm{C}(40 \%$ reduction) whereas in the cross ply laminate the strength diminishes from 1297 to $984 \mathrm{MPa}$ (24\% reduction) at those temperatures.

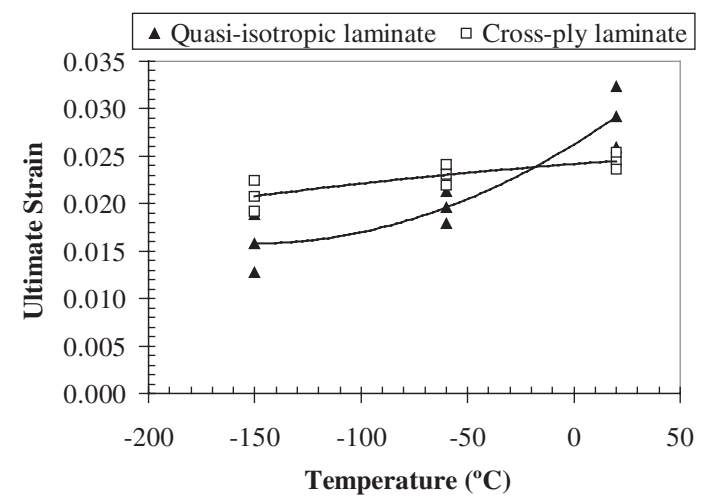

Fig. 6. Static tensile maximum strain versus temperature for cross ply and quasi isotropic laminates. 


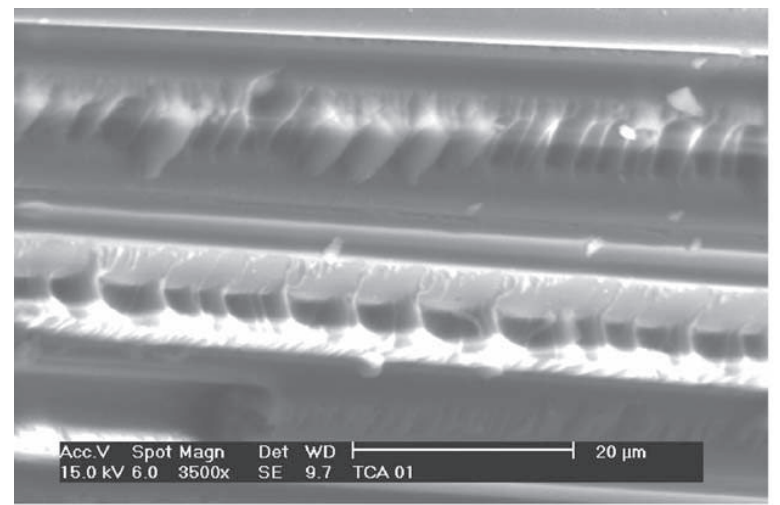

(a)

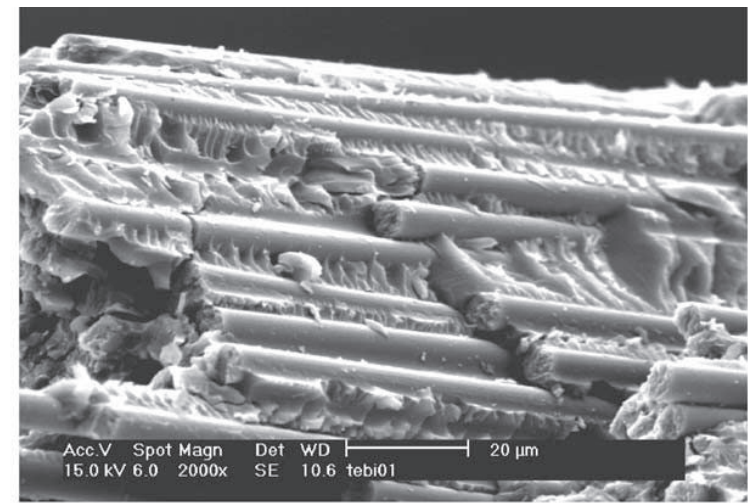

(b)

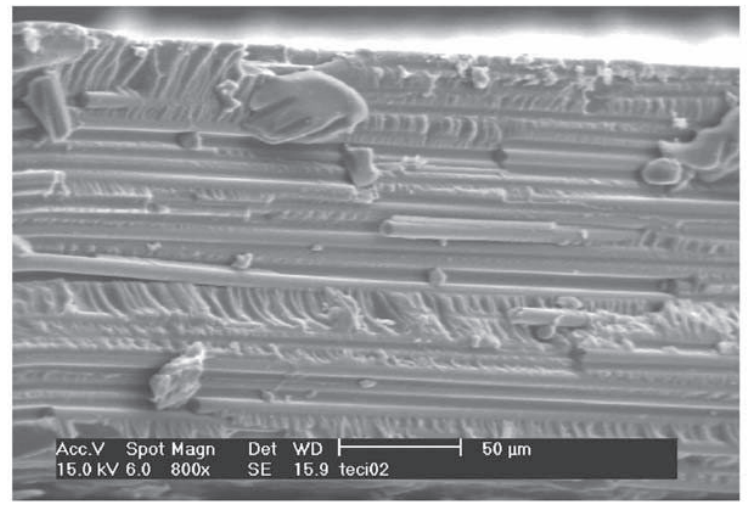

(c)

Fig. 7. Scanning electron microscopy for quasi isotropic laminates broken in tensile tests at (a) $20{ }^{\circ} \mathrm{C}$, (b) $-60{ }^{\circ} \mathrm{C}$ and (c) $-150{ }^{\circ} \mathrm{C}$.

The flexural strength of both laminates is greater than that obtained from the tensile tests at all the considered temperatures, so in the quasi isotropic laminate it is $50 \%$ greater at room temperature, and $60 \%$ greater at $150{ }^{\circ} \mathrm{C}$. In the cross ply laminate, these increments are $57 \%$ at room temperature and $50 \%$ at $150{ }^{\circ} \mathrm{C}$, results which agree with other researchers' conclusions for room temperature tests [23].
In the quasi isotropic laminate, stiffness is also more affected by the temperature change in bending tests than in tensile tests. There is a little increase of this parameter at lower temperatures. (20\% in bending conditions whereas it was $14 \%$ in tensile ones). However, in the cross ply laminate, there is no stiffness change due to temperature in the bending test, a slight drop is observed between room temperature and $60{ }^{\circ} \mathrm{C}$.

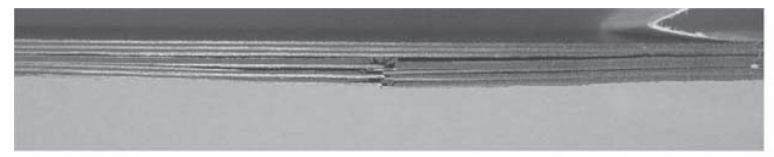

(a)

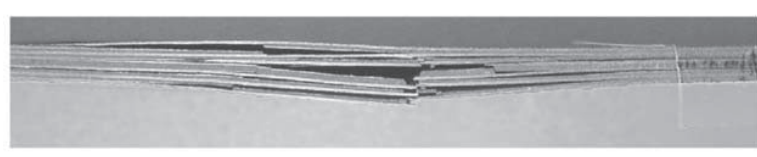

(b)

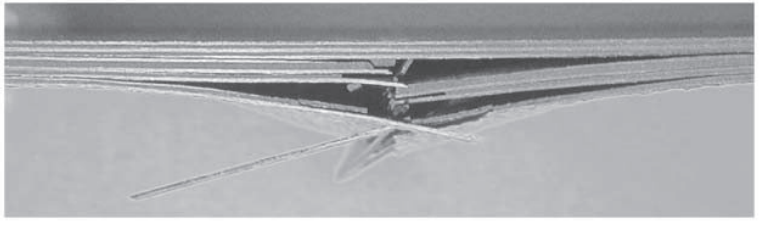

(c)

Fig. 8. Cross ply laminate damage pattern, (a) at $20^{\circ} \mathrm{C}$, (b) at $-60^{\circ} \mathrm{C}$, (c) at $-150^{\circ} \mathrm{C}$. 


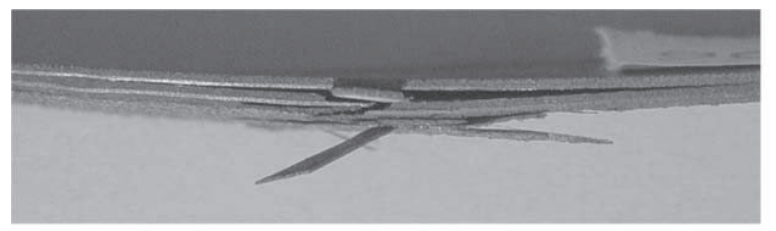

(a)

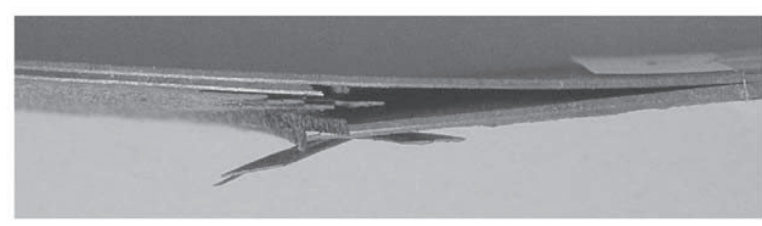

(b)

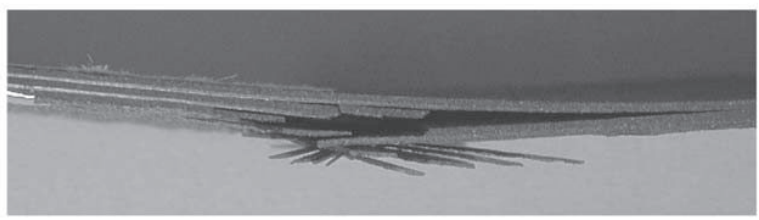

(c)

Fig. 9. Quasi isotropic laminate damage pattern, (a) at $20^{\circ} \mathrm{C}$, (b) at $-60{ }^{\circ} \mathrm{C}$, (c) at $-150{ }^{\circ} \mathrm{C}$.

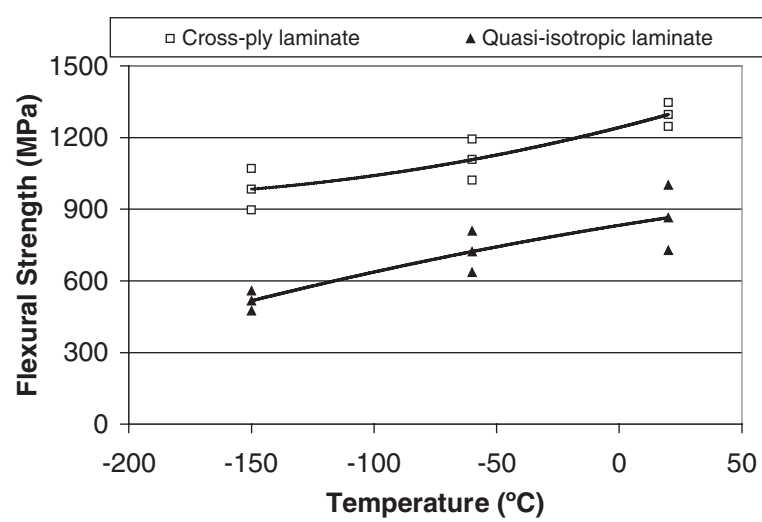

Fig. 10. Flexural strength versus temperature for cross ply and quasi isotropic laminates.

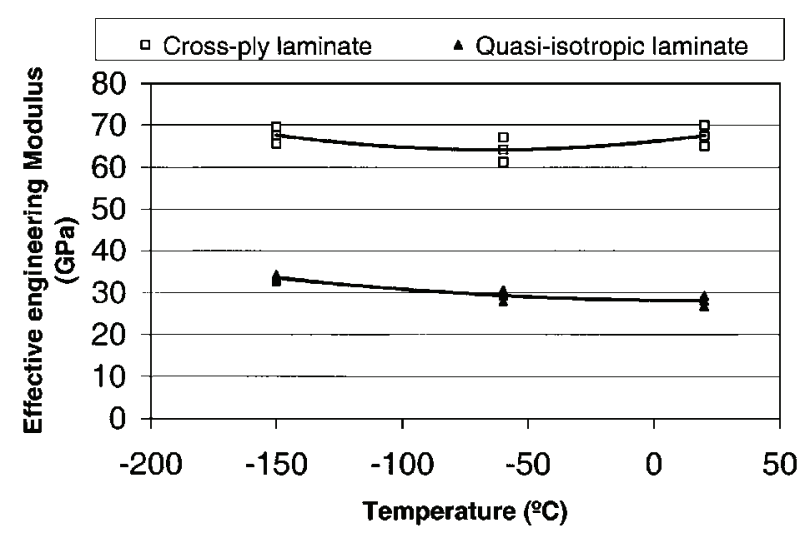

Fig. 11. Effective engineering modulus versus temperature for cross ply and quasi isotropic laminates.

\section{Conclusions}

The results of the mechanical characterization carried out in low temperature conditions for CFRPs with two different stacking sequences (cross ply and quasi isotropic) have shown the reduction of their strength as the temperature decreases, in both tensile and bending conditions. In this last loading condition, CFRP strength, at a given temperature, is greater than that obtained with direct tensile loading. Cross ply laminates show higher values of that property than quasi isotropic ones. Both laminates show that the ultimate TS decreases with temperature. However, the quasi isotropic laminate, with a failure strain higher than that of the cross ply one at $20^{\circ} \mathrm{C}$, is much more affected by lower temperature. Its UTS greatly diminishes with the lowering temperature, and at $150{ }^{\circ} \mathrm{C}$ this property is lower than that of the cross ply laminate. The rupture micro mechanism of CFRPs in tensile conditions changes with temperature. At room temperature, the matrix fails first. As the temperature decreases, the fiber matrix interface becomes much weaker and thus the fibers debond from the matrix.

The stiffness of the quasi isotropic laminate grows as the temperature decreases. In pure tensile conditions, the cross ply laminate stiffness decreases slightly with the lowering of the temperature, remaining practically as constant in the range 20 to $60^{\circ} \mathrm{C}$. In bending conditions, it suffers a small drop of the stiffness in that temperature range although the stiffness at $150{ }^{\circ} \mathrm{C}$ is the same as at $20^{\circ} \mathrm{C}$.

\section{Acknowledgments}

The authors are indebted to the Spanish Comisión Interministerial de Ciencia y Tecnología (Project MAT $98 / 0273$ ) for the financial support of this work. 


\section{References}

[1] Powell RW, Lockwood MK, Cook SA. The road from NASA access to space study to a reusable launch vehicle. Proc 49th Int Astronaut Congress 1989;10 20.

[2] Engström F. Space transport systems for the 21st century. ESA Bull 1998;(95):16 24.

[3] Schutz JB. Properties of composite materials for cryogenic appli cations. Cryogenics 1998;38:3 12.

[4] Dutta PK. Low temperature compressive strength of glass fiber reinforced polymer composites. J Offshore Mech Arctic Engng 1994; 116:167 72

[5] Pintado JM, Carrión JG, García JL, Blas F. Mechanical behavior of composite materials at cryogenic temperature. Proc 4th Eur Conf Compos: Test Std 1998;93 102.

[6] Rogers KF, Phillips LN, Kingston Lee M, Yates B, Overy MJ, Sargent JP, McCalla BA. The thermal expansion of carbon fiber reinforced plastics. J Mater Sci 1977;12:718 34.

[7] Kriz RD. Influence of ply cracks on fracture strength of graphite/ epoxy laminates at $76 \mathrm{~K}$. Effects of defects in composite materials. ASTM STP 1984;836:250 65 .

[8] Wilson JB. Fulmer Research Ltd DP. R1176/D9, 1990.

[9] Dutta PK, Hui D, Alatamirano R. Energy absorption of graphite/ epoxy plates using Hopkinson bar impact. CRREL Report, AD A244 256, 1993.

[10] Adams RD, Gaitonde JM. Low temperature flexural dynamic measurements on PEEK, HTA and some of their carbon fiber composites. Compos Sci Technol 1993;47:271 87.

[11] Reed RP, Golda M. Cryogenic properties of unidirectional compo sites. Cryogenics 1994;34(11):909 28.

[12] Karasek ML, Starit LH, Amateu MF, Runt JP. Effect of temperature and moisture on the impact behavior of graphite/epoxy composites. Part I impact energy absorption. American Society for Testing and Materials; 1995. p. 310.
[13] Shindo Y, Ueda S. Mechanical behavior of cracked woven glass/ epoxy laminates under tension at low temperatures. Cryogenics 1995; 35(11):709 12

[14] Nettles AT, Biss EJ. Low temperature mechanical testing of carbon fiber/epoxy resin composite materials. NASA Technical Paper 3663, 1996.

[15] Hübner R, Hartwing G. Fatigue of cross ply carbon fiber composites at cryogenic temperatures. Adv Cryogenic Engng 1996;42:233 40.

[16] Carrión JG, Pintado JM, García JL. Obtención de propiedades de comportamiento mecánico en materiales compuestos a temperaturas criogénicas. Acta II Congr Nac Mater Compuestos 1997;321 9. in Spanish.

[17] Baschek G, Hartwing G. Parameters influencing the thermal expansion of polymers and fiber composites. Cryogenics 1998;38: 99103.

[18] Kim HS, Wang WX, Taka Y. Effects of temperature and fiber orientation on the mode I interlaminar fracture toughness of carbon/ epoxy composites. Proc 12th Int Conf Compos Mater, ICCM 12 1999;.

[19] Aoki T, Ishikawa T, Kumasawa H, Morino Y. Mechanical behavior of $\mathrm{CF} /$ polymer composite laminates under cryogenic environment. Proc 12th Int Conf Compos Mater, ICCM 121999.

[20] ASTM. Standard test method for tensile properties of polymer matrix composites. D3039, 1989.

[21] ASTM. Standard test methods for flexural properties of unreinforced and reinforced plastics and electrical insulating materials. D790, 1998.

[22] Wilson DW, Carlsson LA. Mechanical characterization of composite materials. In: Rossiter BW, Baetzold RC, editors. Physical methods of chemistry, vol. 7.; 1991. p. 13980.

[23] Wisnom MR, Atkinson JW. Reduction in tensile and flexural strength of unidirectional glass fiber epoxy with increasing specimen size. Compos Struct 1997;38(1 4):405 11. 